\title{
Laboratory Profiles of Pleural effusion Collected from Children: Experience at a Tertiary Care Hospital in Bangladesh
}

\author{
Hasan $\mathrm{M}^{1}$, Islam $\mathrm{MR}^{2}$, Matin $\mathrm{A}^{3}$, Roy $\mathrm{RR}^{4}$, Yusuf $\mathrm{MA}^{5}$, Karim $\mathrm{AKMR}^{6}$, Mowla $\mathrm{MG}^{7}$, Islam $\mathrm{MR}^{8}$
}

\begin{abstract}
Background: Pleural effusion occurs in many reasons. Laboratory tests are necessary to find out the causes. Objective: This study was an attempt to know the laboratory findings of pleural effusion. Methodology: This cross-sectional study of thirty (30) admitted cases with pleural effusion confirmed by chest radiography and aspiration of pleural fluid from one (1) year to twelve (12) years age of either sex were collected purposively. This study was carried out from July 2009 to February 2010 in the Department of Pediatrics at Rajshahi Medical College Hospital. All information were recorded in pre tested semi structured questionnaire. Results: Color of pleural fluid was straw in $56.7 \%$, clear in $30.0 \%$, blood stained in $13.3 \%$. In this study, lymphocyte predominance among $56.7 \%$ cases, acid fast bacilli in $3.3 \%$ cases and raised protein of more than $3 \mathrm{gm} / \mathrm{dl}$ and sugar less then $60 \mathrm{mg} / \mathrm{dl}$ in $93.3 \%$ cases in pleural fluid. Conclusion: In almost all cases protein is raised and sugar is less in pleural fluid. [J Shaheed Suhrawardy Med Coll, 2013;5(1):26-27]
\end{abstract}

Key words: pleural effusion, Cytological of pleural fluid, biochemical analysis of pleural fluid.

Received: August 2012; Revised: March 2013; Accepted: May 2013

\section{Introduction}

Pleural effusions are accumulations of fluid within the pleural space. The fluid enters the pleural space from systemic capillaries in the parietal pleura and exits via parietal pleural stomas and lymphatics. Pleural fluid accumulates when too much fluid enters or too little fluid exits the pleural space. They are classified as transudates or exudates. Asymptomatic transudates require no treatment. Symptomatic transudates and almost all exudates require thoracentesis, chest tube drainage, pleurodesis, pleurectomy or a combination ${ }^{1}$.

It has been reported that, incidence of parapneumonic effusion ranges from $20 \%$ to $91 \%$ with an increase in morbidity and mortality ${ }^{2}$. Parapneumonic effusion is more common in boys than girls and more frequently encountered in infants and young children ${ }^{3}$. Non bacterial infectious agents such as virus and Mycoplasma pneumoniae are the common causes of pleural effusion in children throughout the world. The frequency of viral infection in children is much higher than bacterial infection, though bacteria are more likely than virus to cause pleural effusion. As many as $20 \%$ of these infection can cause small and transient effusion that resolve spontaneously ${ }^{4}$. Out of 176 children with pulmonary tuberculosis, from Spain, $39(22 \%)$ patients had pleural effusion $^{5}$. Chaginaud ${ }^{6}$ found pleural effusion in $10(71 \%)$ out of 14 children with lymphoblastic lymphomas and in 7(12\%) out of 60 children with non-Hodgkins lymphoma ${ }^{6}$.

It is justified to know the laboratory findings in order to avoid delays in confirm diagnosis, proper treatment and outcome of pleural effusion in children.

\section{Methodology}

This cross-sectional study was conducted in the Pediatrics and other respective department of Rajshahi Medical College \& Hospital from July 2009 to Feb 2010. A total number of thirty (30) admitted patients with Pleural effusion, confirmed by chest radiography and aspiration of pleural fluid of one (1) year to twelve (12) years age of

1. Dr. Mahmudul Hasan, Lecturer, Department of Community Medicine, Comilla Medical College, Comilla

2. Dr. Md. Rafiqul Islam, Associate Professor, Department of Pediatrics, Shaheed Shurawardy Medical College and Hospital,

3. Dr. Abdul Matin, Assistant Professor, Department of Pediatrics, Shaheed Shurawardy Medical College and Hospital,

4. Dr. Ranjit Ranjan Roy, Associate Professor, Department of Pediatric Nephrology, Bangabandhu Sheikh Mujib Medical University Dhaka

5. Dr. Md. Abdullah Yusuf, Lecturer, Department of Microbiology, Shaheed Suhrawardy Medical College, Dhaka

6. Dr. A.K.M. Rezaul Karim, Assistant Professor, Department of Pediatrics, Chittagong Medical College, Chittagong

7. Dr. Md.Golam Mowla, Junior Consultant, Shaheed Shurawardy Medical College \& Hospital, Dhaka

8. Dr. Md. Reazul Islam, Medical Officer, Dhaka National Medical Institute \& Hospital, Dhaka

\section{Correspondence}

Dr. Md. Rafiqul Islam, Associate Professor, Department of Pediatrics, Shaheed Suhrawardy Medical College and Hospital, Dhaka - 1207, Bangladesh, Email: rafiq.1956@yahoo.com, Mobile: +8801715067652

Conflict of interest: No conflict of interest

Financial Support: None

Contributions by authors: Dr. M Hasan, Dr. M.R. Islam, Dr. A. Matin \& Dr. R.R. Roy were conducted the study. Dr. M. R. Islam, Dr. A. Matin \& Dr. AKMR Karim have prepared the article. Dr. M.J. Mowla, Dr. M.A. Yusuf \& Dr. M.R. Islam have corrected the paper. 
either sex were selected purposively. The parents were explained about the purpose of the study. Both the written \& verbal consents were taken from the parents without any coercion. When parents did not give consent for any particular case next case was selected. The exclusion criteria were very sick children, age below one year and above twelve years, previously treated pleural effusion cases, Cases having any other chronic illness or co-morbid situation. All information's were recorded in pre tested semi structured questionnaire. Ethical clearance was taken from institutional ethical review board.

\section{Results}

Color of pleural fluid was Straw in $17(56.7 \%)$, clear in $9(30.0 \%)$, blood stained in $4(13.3 \%)$ (Table 1$)$.

Table 1: Physical characteristics of pleural fluid

\begin{tabular}{lcc}
\hline Color & Frequency & Percentage \\
\hline Blood stained & 4 & 13.3 \\
Straw colored & 17 & 56.7 \\
Clear color & 9 & 30.0 \\
\hline
\end{tabular}

Cytological and biochemical analysis showed lymphocyte predominance in $17(56.7 \%)$ cases, malignant cell in 1 $(3.3 \%)$ case and raised protein of more than $3 \mathrm{gm} / \mathrm{dl}$ and sugar less then $60 \mathrm{mg} / \mathrm{dl}$ in $28(93.3 \%$ ) cases (Table 2$)$.

Table 2: Cytological and biochemical finding of pleural fluid

\begin{tabular}{lcc}
\hline Parameters & Frequency & Percentage \\
\hline Lymphocytosis & 17 & 56.7 \\
Sugar $<60 \mathrm{mg} / \mathrm{dL}$ & 28 & 93.3 \\
Protein $>3 \mathrm{gm} / \mathrm{dL}$ & 28 & 93.3 \\
Malignant Cell & 1 & 3.3 \\
\hline
\end{tabular}

Culture was positive (S. pneumoniae) in 2(6.67\%) cases, and no organism was isolated in $28(93.3 \%$ ) cases (Table 3 ).

Table 3: Culture of pleural fluid

\begin{tabular}{lcc}
\hline Culture Result & $\begin{array}{c}\text { Number } \\
(\mathbf{n = 3 0 )}\end{array}$ & Percentage \\
\hline Culture Positive & 2 & 6.7 \\
Culture Negative & 28 & 93.3 \\
\hline
\end{tabular}

\section{Discussion}

In a study at UK conducted by Barnes NP found $96 \%$ of the cases were diagnosed by ultrasonography ${ }^{7}$. However, in this study, X-ray chest and thoracentesis were the main diagnostic tools for the diagnosis. A UK study showed Streptococcus pneumoniae was the commonest causative organism followed by group A Streptococcus, Staphylococcus aureus, Haemophilus influenzae and Coliform $^{7}$. In our study, Streptococcus pneumonia was also the main causative organism. The pleural fluid leukocyte count shows a wide variation in values between non purulent effusion and frankly purulent effusion and predominance of lymphocyte in an exudate should raise the possibility of malignancy or tuberculosis ${ }^{8}$. In our study, lymphocytosis in exudative fluid was due to tuberculosis or malignancy. In a study in Nigerians 167 patients, pleura fluid was predominantly lymphocyte in $83 \%$ of cases, glucose concentration was less than $60 \mathrm{mg} / \mathrm{dl}$ in $54 \%$ and $\mathrm{M}$. tuberculosis was cultured from only $12 \%{ }^{9}$. In this study lymphocyte predominance among $56.7 \%$ cases, acid fast bacilli in $3.3 \%$ case and raised protein of more than $3 \mathrm{gm} / \mathrm{dl}$ and sugar less then $60 \mathrm{mg} / \mathrm{dl}$ in $93.3 \%$ cases. In many developing countries of the world the most common cause of exudative pleural effusion is pulmonary tuberculosis but this is relatively uncommon in united states ${ }^{10}$.

\section{Conclusion}

In almost in all cases protein was raised and sugar was less in pleural fluid. Limitation of this study was small sample size. Some important investigations such as LDH, adenosine diaminase level, pleural biopsy were not possible due to lack of adequate facilities.

\section{References}

1. Pleural Effusion: Mediastinal and Pleural Disorders: Merck Manual P... http://www.merck.com/mmpe/sec05/ch060/ch060d (access on 6/24/2010) 2. Glaucia de Oliveira Moreira, Jose Direcus Ribeiro, Antonia Tere Zinha Tresoldi, utility of a scoring system \& indicative variables of assessing the neck for pleural drainage in peadiatrics patients with parapneumonic pleural effusion, Journal Brasileiro de Pneumologia. 2005; 31: 205-211.

3. Saglari S, Harries KA, Wallis Empyema: The use of broad range 16S rDNA PCR for pathogen detection Chest 2004; 155: 26-30.

4. Hendren WH. Haggery RJ. Staphylococcal pneumonia in infancy and childhood. JAMA 1958; 168:6-16.

5. Merino JM, Carpintero I, Alverz T, et al. Tuberculosus pleural effusion in children. Chest 1999; 115: 26-30.

6. Chaginaud, BE, Bansack TA, Kazade HP et al. pleural effusion in lymphoblastic lymphoma a diagnostic alternative. J Pediatr Surg 1998; 33: $1355-7$.

7. Barnes NP, Hull J, Thomson AH. Medical management of parapneumonic pleural disease. Pediatric Pulmonology 2005;39:127-136. 8. Panitch AB, Papastametos C, Schidlow DV. Abnormalities of the pleural space. In: Taussing LM, Landav LI, eds. paediatric Respiratory Medicine 1999: 1178-96.

9. Onadeko BO tuberculous pleural effusion: Clinical patterns \& management in Nigerians. Tubercle 1978; 59: 269-75.

10. Light RW. Disorder of the pleural, mediastinum \& diaphragm. In: Braunwald E, Faci AS, Kasper DL (eds) Harrison's principles of internal Medicine 15th ed. MC. Graw Hill: 2001:1514. 